Eureka

\title{
France puts flesh on bones
}

\section{Paris}

EUREKA, the French-inspired programme to unite European high-technology industry behind some concrete, profitable and advanced joint enterprises, has a public shopping list at last. Last week CESTA, the Centre d'Etudes des Systèmes et des Technologies Avancees, a public agency with an office in the very courtyard of the French ministry of research, produced a 70-page document listing five "priority action programmes" for Eureka. It is the product of two and a half months of intensive effort by the small and now somewhat fatigued interministerial Eureka group within the French government.

Until the European conference of research and foreign ministers in Paris later this month, the CESTA proposals are the nearest to a bible of exactly what Eureka is - or could be. Only "some" of the proposals are the result of recent shuttle diplomacy; the rest spring from unilateral French imagination.

The CESTA report defines five priorities: computers, networks and communications, robotics, biotechnology, and materials. And in each, it concludes with specific projects, timetables and potential European partners.

Computers dominate the proposais. In a programme dubbed "Euromatic", the Eureka group suggests that Europe should develop by 1992 a "super-Cray", capable of the 30 GigaFlops (floatingpoint operations) per second "required in the design of complex systems". It should be vectorial, use gallium arsenide chips (an as yet unperfected technology), and could link the French companies Bull (once Honeywell-Bull) and Thomson with Siemens in West Germany. Although the market for such machines may be small, they are becoming so "essential" in certain key applications that Europe should develop a strategic independence in the technology from the present US and, shortly, Japanese suppliers.

Also under "Euromatic", the French group identifies a need to study "highly parallel" computer architectures aimed at a machine of 10 GigaFlops by 1992 , via a demonstration machine 100 times less powerful by 1988 . This would involve collaboration between Bull, Thomson and the German computer company GMD, which would "form the core of a broader European team including other partners (for example Britain, Italy)"

Other Euromatic projects include the development of high-capacity mass memory, starting with "giant" magnetic disks and moving on to optical disks (Bull, plus BASF and Siemens of West Germany); a software engineering centre (five companies in France, four in West Germany plus Aachen University, Philips in the Netherlands and ICL, Logica and Scicon of Britain are suggested); artificial intelligence applied to "four precise projects" (nine companies and one university in France, four companies in Britain, Olivetti of Italy, Norsk Data of Norway and Philips and the University of Amsterdam could be involved); and there would be work on synchronous architectures, dedicated circuits and symbol processors.

The prospectus also lists projects on expert systems, multilingual access to databases, the management of large-scale industrial processes, a European microcomputer "paving the way to advances in integrated circuitry and the image processing industry, now a US monopoly", a 64-megabit dynamic memory and a European development unit for gallium arsenide technology and custom circuits.

Euromatic is by far the most specific of the five "priority actions". In robotics ("Eurobot"), France proposes the development of intelligent semiautonomous robots for repair and maintenance in hostile environments (such as nuclear reactors), an entirely automatic agricultural tractor (Renault, Fiat and Saab could be interested), flexibleproduction factories (using computerautomated design and manufacture) and carbondioxide, carbonmonoxide, excimer and free-electron lasers as machining tools

"Eurobio" involves the production of new crops and varieties for the seed industry, and the development of crops "as a means of transforming industrial processes"; and the research and development of systems for the control and regulation of biochemical processes (including biochemical reactors and novel means of drug delivery). The objective in the seed industry would be to give Europe "a leading position" on the world seed market, estimated to be worth some $\$ 10,000-12,000$ million, and some two dozen European companies, institutes and universities are identified as potential partners.

Add to these programmes "Eurocom" (communications) and "Euromat" (the development of a ceramic turbine) and you have a list of most of the high technology challenges facing not just European but all developed-world industry. So what is special about Eureka? First, the sense of urgency. Second, the fact that even the ideological French have discovered pragmatism; they say here that "nothing is fixed" about Eureka except that some practical actions should be under way by the end of this year. The key is probably government backing. "We don't expect governments to be coming with their chequebooks" to the Eureka conference later this month, they say, "but we do want to define the structure of financing". Which means it is time to say who will pay, and how.

\section{UNESCO \\ Reforms now under way}

Washington

A SERIOUS attempt is being made by the United Nations Educational, Scientific and Cultural Organization (UNESCO) to answer criticisms by Western nations. The executive board, meeting in Paris, has urged strengthening UNESCO's scientific and environmental activities, which are generally well thought of, but also put limits on more controversial programmes such as "Communication in the service of man". US officials seem pleasantly surprised by reports of the meeting but stress that no immediate decision to rejoin is on the cards.

Decisions taken at the marathon sixweek meeting in Paris are not binding on the organization; they will however be put to the UNESCO general assembly next October in Sofia, Bulgaria, where all 260 member countries will be represented. The most pressing task has been to plan a $1986-87$ biennium budget that is 25 per cent lower than the previous biennium, due to the withdrawal of the United States. Western nations (particularly Britain, which has also threatened to withdraw unless there are improvements) wanted to see the selective elimination of programmes that were judged to be either wasteful or opposed to Western interests; the Soviet Union, on the other hand, wanted to see a 25 per cent reduction across the board. So far, the West seems to have had its way.

The communications programme, for example, has been made uncontroversial by strictly limiting its more theoretical aspects, while devoting most of the funds for this topic into training of journalists. The Intergovernmental Programme on Man and the Biosphere, the International Geological Correlation Programme and the International Hydrological Programme, on the other hand, have been recommended for strengthening.

There has also been a reduction in the number of subprogrammes in the draft budget (another Western bugbear), and the whole plan has been presented in a new format that breaks with convention by being relatively easy to understand. Cost-benefit analysis is used explicitly, apparently for the first time.

The executive board has essentially ended up with a zero growth budget, with all activities beyond those that can be paid for after the 25 per cent budget reduction placed in a special category. The board suggests that similar planning should be adopted if Great Britain and Singapore do withdraw after the next assembly, as threatened. The changes so far at UNESCO, though pleasing to Western eyes, are not considered likely to make Britain change its mind. 